\section{Desenvolvimento histórico-epistemológico da Epidemiologia e do conceito de risco}

\author{
The historical and epistemological development \\ of epidemiology and the concept of risk
}

\begin{abstract}
Statistical reasoning in health practice was disseminated by epidemiology and is widely used in various health fields. This paper revisits the historical development of epidemiology and the concept of risk, responsible for the use of statistical chance as part of causal thinking in health sciences. The study covered the period from 1872 to 1965, and the documental base consisted of scientific articles related to the development of epidemiology as a field, particularly in the American Journal of Hygiene, as well as scientific books. Three phases were identified in the development of epidemiology: constitution, exposure, and risk. The article proceeds to discuss epistemological and social and health aspects required for the historical understanding of each phase. It concludes by stressing the relevance of critical reflection on epidemiological science and its relationship to health practice, especially in public health, in order to optimize its current use and foster its on-going creative reconstruction.
\end{abstract}

Risk; Epistemology; Social Medicine
José Ricardo de Carvalho Mesquita Ayres ${ }^{1}$

\section{Introdução}

É sabido que o interesse no reconhecimento, em escala populacional, das desigualdades no adoecer humano emergiu no final do século XVIII e início do XIX, tornando-se potente instrumento da construção das sociedades modernas 1. Em conformidade com todo o amplo movimento iluminista, passou-se, desde então, a buscar as "leis" socionaturais do adoecimento, objetivando conhecer e dominar, por meios racionais, as condições de vida e saúde das populações humanas e construir a utopia da sociedade plenamente saudável 2 .

Foi com base nesses saberes, ainda identificados como Higiene Social ou Pública, que a Epidemiologia iniciou seu processo de conformação científica. Na segunda metade do século XIX, desenvolveram-se procedimentos sistemáticos para conhecer a mecânica de interdição ou facilitação que o meio ${ }^{3}$ produzia sobre os eventos fisiopatológicos, progressivamente identificados pelas ciências médicas da época. Este processo permitiu à incipiente ciência epidemiológica relacionar causalmente os fenômenos do organismo humano às condições de vida das populações nos termos das ciências positivas modernas 4 .

Ao longo do século XX, observa-se importante inflexão nessa trajetória. A Epidemiologia, que buscava identificar exaustivamente os determinantes externos do adoecimento, integrando-os nas totalidades sintéticas designadas como meio 
externo, passou a delimitar relações causais analíticas e abstratas, na forma de associações de caráter probabilístico. Traduzidas no conceito de risco epidemiológico, este construto torna-se elemento central para as práticas de saúde atuais 5 . O objetivo do presente artigo é recuperar as principais etapas históricas desse processo, demonstrando como, pela formalização do conceito de risco, o caráter probabilístico passou a instruir o raciocínio causal em epidemiologia, com repercussões nas ciências biomédicas em geral.

\section{Método}

Trata-se de um estudo de caráter transdisciplinar, situado nas fronteiras entre a Saúde Pública, a Medicina Social, a História e a Epistemologia. Seu desenho está apoiado em uma metodologia que pode ser genericamente descrita como uma epistemologia histórico-crítica 6 .

Com tal denominação quer-se apontar, em primeiro lugar, a escolha do desenvolvimento dos conceitos como o fio condutor da narrativa histórica que sustenta o estudo. Sob essa perspectiva, os conceitos atuais de uma ciência são entendidos como ponto de maior desenvolvimento de uma racionalidade aplicada 7 , cuja construção busca-se recuperar desde suas primeiras manifestações específicas - no chamado método da recorrência 8 . Não se trata, portanto, de um exame estritamente lógico-formal da construção do conceito, mas da sua significação no âmbito da racionalidade da prática científica à qual pertence.

Em segundo lugar, quer-se assinalar uma concepção de racionalidade que a toma como expressão de uma ação comunicativa ${ }^{9}$. A construção dos conceitos é entendida, nesse sentido, como uma prática discursiva ${ }^{10}$, isto é, como a produção de proferimentos que aspiram à expressão de juízos intersubjetivamente válidos sobre determinada esfera da realidade. Tal pretensão - e seu sucesso ou insucesso - tem por base a capacidade de esses discursos produzirem comunicação e entendimento sobre algo entre os sujeitos de uma comunidade de prática - no caso, a dos cientistas entre si e deles com a sociedade de modo mais geral. Esta validade se apoia na coerência lógica e verificação empírica dos proferimentos (validade proposicional), mas também, e inextricavelmente, no reconhecimento do interesse prático e correção moral desses proferimentos (validade normativa) e na autenticidade e legitimidade de sua formulação (validade expressiva).

Em terceiro lugar, quer-se também apontar que o exame de um discurso científico, ao julgar as condições de validade a que respondeu his- toricamente, requer, por sua vez, a explicitação das pretensões de validade do próprio discurso histórico-epistemológico que se debruça sobre ele. Por isso, será sempre desde uma perspectiva crítica que essa epistemologia histórica se realiza, isto é, dependerá sempre do livre e público exame de seus próprios critérios de interpretação da validade do discurso científico estudado.

Assim, o desenvolvimento da Epidemiologia será narrado aqui como a história da construção do discurso conceitual do risco, tomando-se sempre como contraponto uma análise crítica dos personagens, contextos sociais e institucionais, recursos teóricos e técnicos, valores e aspirações que foram conformando, e sendo conformados também, por esse discurso. Os aspectos "internos" e "externos" 11 na conformação da ciência epidemiológica são aqui articulados em uma totalidade de sentido que confere significado aos conceitos estudados, em um movimento de mútua referência entre parte e todo, chamado de "círculo da compreensão" ou "círculo hermenêutico" 12 .

O período trabalhado situa-se entre 1872 e 1965 , por considerar-se que esse período abrange os principais movimentos de constituição da Epidemiologia como ciência moderna.

A base documental do estudo foi constituída de fontes primárias e secundárias. As fontes primárias foram os artigos de periódicos científicos pelos quais a produção epidemiológica foi sendo organizada e difundida, em particular o American Journal of Hygiene, atual American Journal of Epidemiology (96 documentos), artigos de outros periódicos de relevância - The Lancet, Proceedings of the Royal Society of Medicine, American Journal of Public Health, The Journal of Experimental Medicine, The Journal of Hygiene, Journal of Preventive Medicine, Annals of the American Academy of Political and Social Science, British Medical Journal, Human Biology, The New England Journal of Medicine, Journal of Chronic Diseases, Journal of Public Health - e publicações científicas da época, como livros, brochuras e boletins (85 documentos). Esse material constituiu o corpus que permitiu mapear a construção do discurso epidemiológico, especialmente por conta de sua "internalidade". As fontes secundárias foram artigos e livros de diferentes épocas e áreas, sobretudo de História da Medicina, da Saúde Pública e da Epidemiologia, História Geral, Ciências Sociais e biografias, as quais permitiram compreender as relações entre os movimentos internos da Epidemiologia e sua "externalidade", vale dizer, as personagens, instituições, práticas e contextos sociais envolvidos em sua história. Em razão dos limites de espaço do artigo, só serão referidos aqui os textos mais centrais para a narrativa. Para maior aprofundamento e listagem completa das 
referências, pode-se consultar o estudo em que se baseia este artigo 13 .

\section{Da constituição ao risco: um novo discurso entre as ciências biomédicas}

Se fosse preciso resumir em uma única expressão a ideia mais centralmente representativa do processo de construção da linguagem epidemiológica e da formalização do conceito de risco, essa expressão seria tecnopragmatismo. Por tecnopragmatismo quer-se aqui referir à tendência de organização do saber epidemiológico em torno de objetos eminentemente práticos $\mathrm{e}$ métodos substantivamente aplicados, isto é, por sua positividade e produtividade quanto à identificação e transformação de fenômenos diretamente relacionados a necessidades de proteção ou recuperação da saúde de indivíduos e grupos populacionais.

Esse tecnopragmatismo correspondeu a um duplo e articulado movimento epistemológico. De um lado, transitou-se das concepções ontológicas da Higiene do século XIX a concepções processuais dos fenômenos epidêmicos, isto é, abandonou-se a pretensão de tomar como objeto de conhecimento o fenômeno epidêmico, em si mesmo, em favor do conhecimento de aspectos parciais do comportamento epidemiológico das doenças. De outro lado, o interesse do conhecimento transitou de pretensões teóricas a pragmáticas, quer dizer, da ambição de formular "leis gerais" de determinação dos fenômenos epidêmicos, passou-se à pretensão de desenvolver investigações epidemiológicas na justa medida de sua relevância para a apreensão e manejo técnico dos problemas de interesse para o campo da saúde. Na apreensão e interpretação desse movimento, foram delimitadas três etapas de desenvolvimento da Epidemiologia: Epidemiologia da Constituição, Epidemiologia da Exposição e Epidemiologia do Risco (Figura 1).

Pode-se entender as etapas acima apontadas, e o tecnopragmatismo que as subjaz, como a crônica do desenvolvimento de um discurso sobre os fenômenos de saúde e doença caracterizados por três traços fundamentais: controle técnico dos processos saúde-doença como interesse prático (horizonte de validação normativa do discurso epidemiológico), comportamento coletivo dos fenômenos de saúde e doença como seu campo específico de objetividade (esfera de validação proposicional de seu campo científico) e variação quantitativa como forma de traduzir esse comportamento em linguagem científica (modo de validação expressiva dos sujeitos participantes de sua comunidade científica).
O período, ambiente e personagens cobertos por este estudo, no trajeto da Epidemiologia da Constituição à Epidemiologia do Risco, serão, em última análise, a história das diversas conformações experimentadas por essa tríade discursiva: "controle técnico - comportamento coletivo variação quantitativa”.

Embora os primeiros movimentos de aplicação de métodos quantitativos em saúde remontem ao século XVII, na Inglaterra, marcado pelo trabalho de John Graunt 14, a conformação discursiva característica da Epidemiologia só irá

Figura 1

Representação esquemática das fases de desenvolvimento histórico-epistemológico da epidemiologia, relacionando tipo de estudo, natureza do objeto e pesquisadores paradigmáticos.

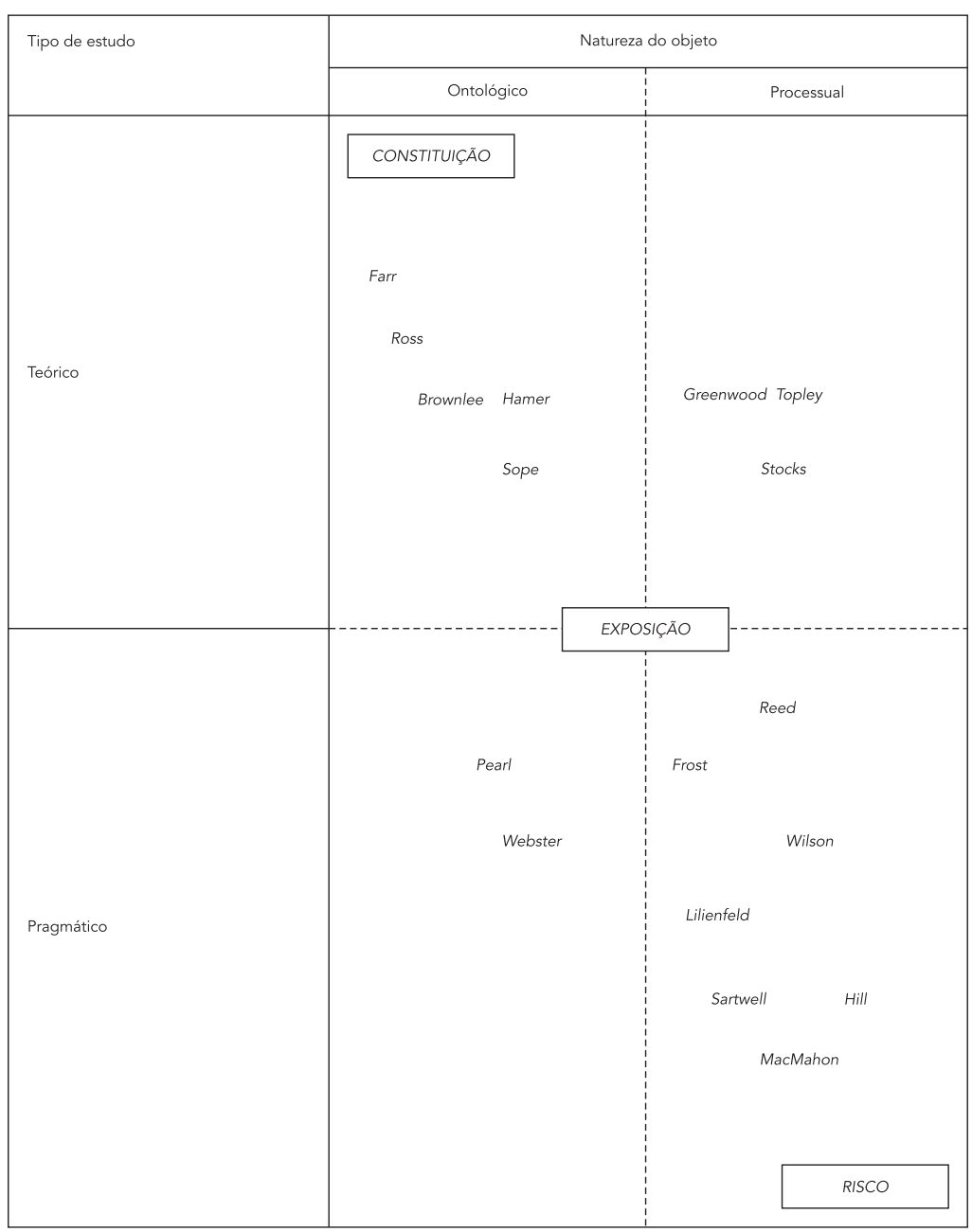


emergir no cenário acadêmico no final do século XIX e início do século XX, especialmente no contexto da moderna Saúde Pública norte-americana. A chamada Epidemiologia Moderna foi capitaneada por Wade Hapton Frost 15 (Figura 2) desde o pioneiro Departamento de Epidemiologia da Johns Hopkins School of Hygiene and Public Health (SHPH). De onde vem o impulso histórico para isso? A que projeto social e sanitário está vinculado tal tipo de interesse? A resposta não é simples, mas talvez possamos sintetizá-la na afirmação de que é do projeto de um reformismo social cientificamente fundado que nasce o impulso central desse movimento.

Figura 2

Wade Hampton Frost (1880-1938).

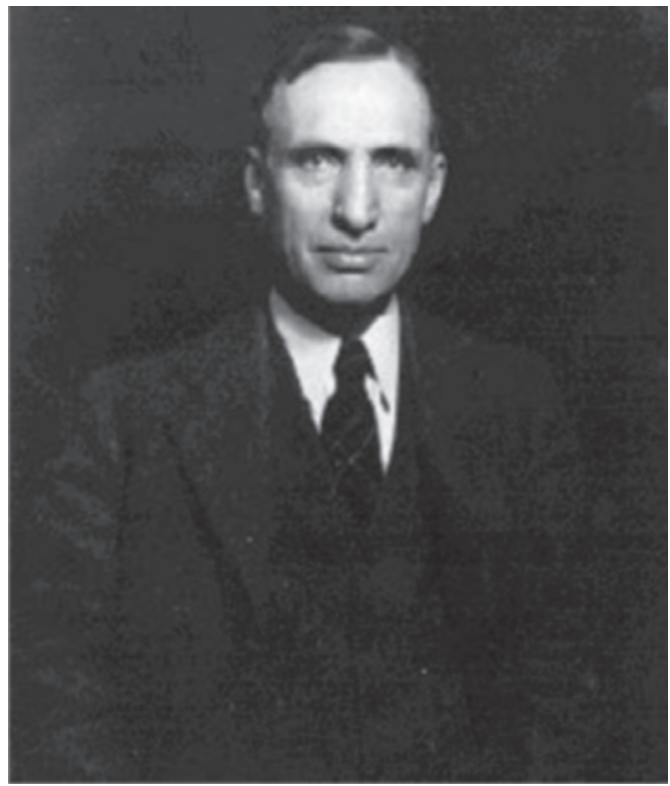

Crédito: Virginia University (domínio público).

A criação da SHPH foi uma acabada expressão desse processo. Tomemo-la, assim, por sua situação emblemática e por sua decisiva influência político-institucional, como eixo condutor de nossa narrativa. Criada em 1916, em Baltimore, Estados Unidos, a SHPH representou, no campo da saúde, uma ampla onda de reformas que sofreu o ensino universitário norte-americano com vistas à modernização e desenvolvimento social dos Estados Unidos. Financiado especialmente pela Fundação Rockfeller 16, a reforma visava substituir o perfil elitista e filosófico-humanista predominante nas universidades norte-americanas por um ensino pragmático, voltado para o desenvolvimento tecnológico exigido pela radical guinada industrial do país, particularmente desde o final da Guerra de Secessão 17.

Quando William Welch montou a estrutura e o corpo docente da SHPH, tinha como projeto produzir um conjunto de conhecimentos e técnicas que superassem o sentido que considerava excessivamente ideológico da então chamada "velha saúde pública". Na Alemanha, no Instituto de Higiene, criado em 1872 por Max Von Pettenkofer (Figura 3) em Munique, Welch encontrou o modelo de investigação científica que buscava para sua escola 17 .

O Instituto de Higiene de Munique oferecia um poderoso apelo para o projeto de modernização científica da Saúde Pública que Welch procurava: a combinação de rigorosas observações de fenômenos populacionais com pesquisa laboratorial de base fisiológica. Pettenkofer, como uma espécie de Claude Bernard da Saúde Pública, propôs tratar as questões sociossanitárias como uma "macrofisiologia", buscando identificar empiricamente os mecanismos favoráveis e desfavoráveis à saúde dos indivíduos e comunidades, apoiando-se nos cânones e procedimentos da ciência experimental. Dava, assim, uma contribuição decisiva para que se conformasse a base discursiva da Saúde Pública e da Epidemiologia modernas.

Riqueza material, industrialização, o puritanismo, o pragmatismo de James e Dewey, a ampla penetração do darwinismo, todos esses aspectos articulados fizeram do ambiente cultural, político e científico-filosófico dos Estados Unidos do início do século $\mathrm{XX}^{18} \mathrm{o}$ solo ideal para que prosperasse lá, como talvez em nenhuma outra parte do mundo, o moderno discurso científico da Higiene, tal como praticado no Instituto de Higiene de Munique.

\section{Epidemiologia da Constituição}

Na Epidemiologia que começa a se organizar desde a Higiene de Pettenkofer, o comportamento coletivo das doenças é entendido como expressão das condições insalubres resultantes das interações em um dado meio de organismos humanos entre si e com organismos não humanos, assim como elementos externos não orgânicos. $\mathrm{O}$ comportamento epidêmico revelava não apenas o encontro entre um germe e populações humanas, como postulava a visão bacteriológica, mas a resultante desse encontro na economia das funções vitais de indivíduos e grupos humanos. 
Figura 3

Max Joseph von Pettenkofer (1818-1901).

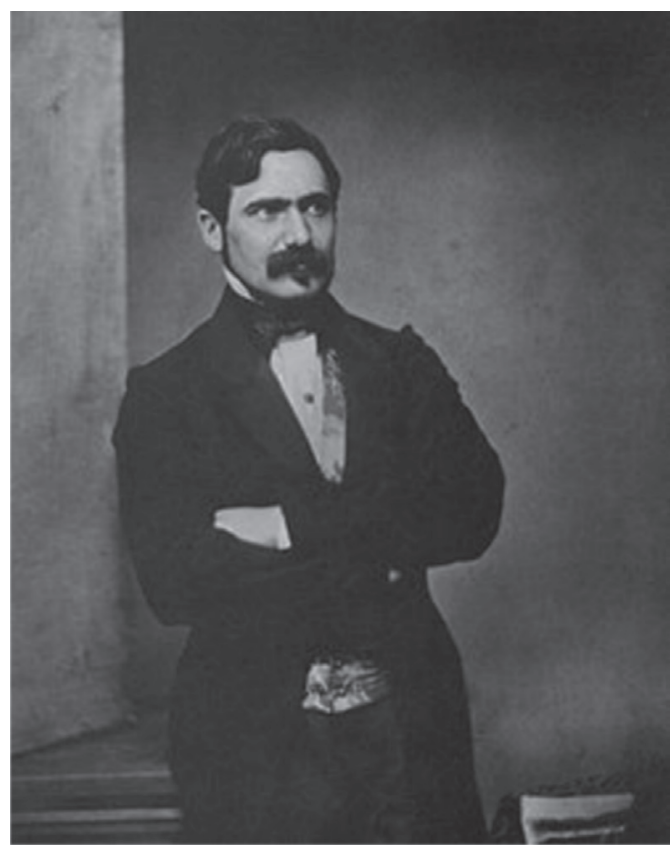

Crédito: Franz Hanfstaengl (domínio público).

As características objetivas do fenômeno epidêmico passaram a ser constatadas com o intermédio da distribuição dos casos, descrita segundo critérios analíticos de lugar e tempo. Descrever os casos conforme esses critérios era, imediatamente, atestar o caráter das interações entre meio e organismos, resultantes de características constitucionais de ambos e explicativos das "disfunções" sociossanitárias resultantes 19.

A busca de equações de lugar e tempo que conferissem identidade objetiva aos movimentos de favorecimento ou perturbação da economia funcional de populações foi, assim, conformando a primeira objetividade propriamente "epidemio-lógica”. A resultante das diversas influências que favoreciam ou obstaculizavam a saúde era sintetizada, na terminologia pettenkoferiana, pelo chamado "fator y", ou seja, as condições do meio que tornavam as populações efetivamente suscetíveis aos agravos à saúde, uma espécie de tradução científica positiva da antiga noção metafísica de miasma ${ }^{20}$. Ainda que grande parte das proposições teóricas de Pettenkofer tenha sido superada já no final do século XIX, sua obstinada defesa da síntese que uma Higiene científica devia buscar na apreensão dos diversos deter- minantes da distribuição populacional dos fenômenos de saúde e doença deu visibilidade à particularidade do objeto epidemiológico. Essa particularidade permitiu à Epidemiologia distinguir-se da Bacteriologia e construir sua identidade científica, alcançando uma mais clara e nova importância no início do século XX, particularmente relevante no contexto da Nova Saúde Pública dos Estados Unidos.

Os trabalhos epidemiológicos apresentam, no início do século XX, uma abertura ainda grande de motivos e metodologias, o que era esperado num campo científico no estágio de desenvolvimento da Epidemiologia de então. Há, no entanto, um denominador comum a todos eles: a identidade que buscam estabelecer entre a variação quantitativa de fenômenos coletivos e uma constituição ambiental desfavorável à saúde.

A primeira fase da produção epidemiológica capitaneada pela Johns Hopkins pode ser resumida, com efeito, como um conjunto de estudos populacionais. Esta designação busca diferenciar o estudo epidemiológico daqueles de outras áreas científicas da saúde, seja no que se refere ao seu substrato empírico (seres humanos, não cobaias; coletivos, não indivíduos), seja aos seus desenhos de estudo (eventos espontâneos, não experimentais; estudos de campo, não laboratoriais), seja às suas problemáticas (sanitárias, não clínicas ou fisiopatológicas).

Predominava nesses estudos populacionais um caráter descritivo. Esse caráter eminentemente descritivo tinha como escopo fundamental expor à apreciação pública, ao menos à comunidade acadêmica, determinados aspectos ou condições relativas à constituição sanitária de um local, população ou grupo, não acessível ao senso comum.

As descrições desses estudos não dependiam de procedimentos quantitativos sofisticados, e nem havia ainda facilidades técnicas e teóricas que estimulassem a produção nessa direção. Os procedimentos descritores se resumiam em sua quase totalidade a taxas e coeficientes de mortalidade, morbidade, dados demográficos ou dados biométricos. As aplicações matemáticas requeridas para a construção desses indicadores eram de uma natureza predominantemente aritmética. As inferências objetivas passavam ao largo da análise matemática, a qual só ocorre, e num sentido fraco da expressão, no momento do despretensioso e rudimentar tratamento estatístico que recebiam. A validação do conhecimento epidemiológico mantinha ainda o instrumental matemático em posição subordinada às teorias já consagradas na Higiene Social, sintetizadas na noção hipocrática de constituição epidêmica - termo utilizado pelo clínico inglês Sydenham, 
no século XIX, mas reutilizado e ressignificado nesse período, especialmente pelos ingleses, no sentido genérico de um meio propício às manifestações mórbidas de um tempo e lugar determinados 21,22 .

Na Epidemiologia da Constituição, o conceito central do raciocínio causal e a busca de evidências empíricas para sustentá-lo era, como apontado acima, o conceito de meio externo. Vimos que esse conceito traduziu os determinantes extraorgânicos da saúde em função de uma mecânica de interdição/facilitação de processos favoráveis ou desfavoráveis para a economia vital. Porém, conforme a Epidemiologia foi se formalizando cientificamente, o conceito de meio externo foi gradualmente substituído pelo conceito de risco.

\section{Epidemiologia da Exposição}

Os anos 20 do século XX foram repletos de acontecimentos de enorme significação para a compreensão do modo como evoluiu o discurso epidemiológico. Naturalmente não se pode aqui fazer mais que indicá-los de forma genérica e superficial, mas cabe destacar, de todo modo, a Grande Depressão do final da década, de um lado, e, de outro lado, o espantoso progresso científico e tecnológico das ciências de um modo geral e das ciências biomédicas em particular.

Destaca-se o primeiro aspecto porque ele foi um poderoso fator de tensão para o ambiente cultural e político da época, com forte influência no desenvolvimento da Epidemiologia. A crise econômica e social do pós-I Guerra abriu espaços importantes para uma consciência social mais forte e um maior intervencionismo do Estado, inclusive nos Estados Unidos, na regulação das relações de produção e organização social, de modo geral. Foi nesse ambiente que os Estados Unidos elegeram o democrata Roosevelt e sua plataforma do New Deal, que priorizava ações voltadas para a saúde pública 23 . Foi assim que o epidemiologista Frost assumiu, em 1931, a direção da SHPH, demonstrando o prestígio da Epidemiologia no projeto da saúde pública nesse contexto 17.

Mas o segundo aspecto acima levantado é também fundamental para entender as transformações experimentadas pela Epidemiologia: os enormes progressos tecnocientíficos da área biomédica, sobretudo os progressos da Imunologia, pressionaram de forma impressionante toda a busca de conhecimento das forças favoráveis ou desfavoráveis à saúde. Abre-se um espaço sem precedentes para a Saúde Pública e a Epidemiologia, mas ao mesmo tempo esperase delas, mais do que nunca, o diálogo com os conceitos e métodos das ciências que se ocupavam da saúde no plano fisiopatológico, especialmente com as relações entre agente infeccioso e resposta imunológica. O sucesso na resposta a esse desafio vem particularmente do trabalho de Frost, nos Estados Unidos, e de Greenwood e Topley, na Inglaterra.

Topley, bacteriologista e imunologista, e Greenwood, estatístico e epidemiologista, professores da London School of Higyene and Tropical Medicine, inspirados por uma longa tradição quantitativista que remonta a nomes como Farr, Brownlee, Hamer e Ross, realizaram um fecundo casamento entre a análise matemática de eventos populacionais e a pesquisa experimental de eventos imunológicos, gerando uma verdadeira revolução dentro da Epidemiologia e fora dela, favorecendo o progresso da própria Imunologia 24 .

A noção de constituição epidêmica foi sendo substituída por formulações mais pragmáticas e estreitamente relacionadas com o conhecimento biomédico, como o conceito de "potencial epidêmico" 25. Os estudos epidemiológicos passam, desde aqui, a procurar a relação entre os casos de uma doença e as populações expostas, entendida como função matemática das chances de contacto entre infectados e suscetíveis, como oportunidade de exposição ao agente causal. Eis aqui o discurso da Epidemiologia da Exposição, base para a formalização do conceito de risco.

Valendo-se dessa lógica das oportunidades de exposição, duas alternativas se abriram para a construção de enunciados objetivos na Epidemiologia. Uma, de perfil mais teórico, buscou estabelecer qual conjunto de condições deveria estar presente para expor os membros de uma população à infecção por um determinado agente, traduzindo matematicamente a mesma orientação epistemológica genérica da etapa anterior. A outra, no mesmo sentido, mas na direção inversa, buscava reconhecer o que a ocorrência de casos de uma doença em uma população permitia inferir sobre a influência de uma dada condição a que esta população esteve submetida. A primeira buscava apreender e representar, por funções matemáticas, um conjunto de aspectos que expunha as populações a determinadas infecções. A segunda buscava indicadores matemáticos de aspectos estratégicos para apreender e transformar a conformação dessas situações. A primeira partia dos antecedentes para tentar prever as consequências. A segunda partia das consequências para identificar antecedentes que pudessem explicá-las. Na primeira, risco expressava o efeito negativo configurado pelo conjunto dos determinantes da exposição. Na segunda, risco passou a indicar a relevância de um dado fator de exposição na ocorrência de um problema. 
Um passo fundamental para que esta segunda tendência, mais pragmática e tecnicamente operacional, se tornasse hegemônica, foi o uso da lógica probabilística para mensurar e analisar a chance de associação entre um determinado evento e um antecedente causal, ou fator de exposição. Stocks 25 e Greenwood 26, na Inglaterra, e Frost 27, nos Estados Unidos, foram os principais responsáveis por esse passo. Incorporado à Epidemiologia, a lógica da probabilidade e seu manejo estatístico possibilitaram uma extraordinária e diversificada capacidade de analisar e testar a participação de fatores socioambientais e comportamentais na ocorrência e distribuição das doenças, especialmente das infecciosas, dominantes na época.

Desse modo, a problemática epidemiológica foi conduzida à definitiva ultrapassagem da fronteira entre o teórico e o pragmático. De um lado, o controle estatístico das incertezas, de que a complexidade e as lacunas dos dados populacionais nunca poderiam estar absolutamente livres, e, de outro lado, a plausibilidade biológica como balizadora dos limites da validade científica dos enunciados produzidos, permitiram à Epidemiologia delimitar e quantificar uma variedade potencialmente ilimitada de relações de exposição de interesse. Essa suscetibilidade ao contacto infectante estatisticamente inferida passou a ser o conteúdo fundamental das primeiras formulações matematicamente formalizadas do risco epidemiológico.

Com a maior precisão na formulação de suas questões e no controle da credibilidade de suas respostas, a utilização e o prestígio científico do conhecimento epidemiológico avançaram rapidamente. Vários outros aspectos técnicos concorreram para consolidar esse processo, entre eles destacam-se, de um lado, o estudo epidemiológico de coletivos humanos mais restritos, como núcleos familiares, escolas, creches, ambientes de trabalho, conferindo aos desenhos uma agilidade operacional inédita e contribuindo para um rápido e diversificado acúmulo de informações teóricas e metodológicas, e, de outro lado, o progresso dos métodos estatísticos, que desde as publicações de Fisher, a partir da segunda metade dos anos vinte do século passado, difundiam-se amplamente entre os epidemiologistas e permitiam relacionar os fenômenos apreendidos naqueles coletivos restritos a comportamentos epidemiológicos de dimensão populacional 28.

\section{Epidemiologia do Risco}

Em meados do século XX, ao término da II Grande Guerra Mundial, uma série de transformações ocorreu nas práticas médicas e sanitárias. Pre- ventivismo e securitarismo passam a dominar o cenário das práticas de saúde, especialmente nos Estados Unidos.

Preventivismo e securitarismo são duas ideias tão inter-relacionadas quanto repletas de contradições, com as quais lidamos ainda hoje. O preventivismo pode ser sintetizado como a doutrina que retraduz a concepção ampliada de determinação do processo saúde-doença, tal como desenvolvida pelas disciplinas ligadas ao campo da Higiene e da Saúde Pública desde o século XIX, em práticas de caráter eminentemente técnico, essencialmente dirigidas ao âmbito dos cuidados individuais e apoiadas em ações assistenciais e educativas simplificadas, com baixa densidade de tecnologia especializada e equipamentos materiais 29. O securitarismo consiste, basicamente, na assunção da responsabilidade privada pela conquista do bem estar e da saúde, a qual se apoia num sistema assistencial de níveis de elevada e progressiva sofisticação tecnológica e especialização, com acesso organizado segundo sistemas meritocráticos de base atuarial - quanto mais recursos investidos pelos indivíduos, melhores e mais completos os serviços de assistência provisionados por suas seguradoras públicas ou privadas 30 . Ambas as tendências "capturaram" o desenvolvimento da Epidemiologia, interpelando-a para fornecer subsídios para o controle e monitoramento das chances de adoecimento dos indivíduos, conforme suas diversas situações sociodemográficas e comportamentais.

Nos Estados Unidos do pós-guerra a situação era de pujança material, vitalidade econômica e hegemonia política internacional, dando margem a uma onda de liberalização da economia e enfraquecimento das posições pró-intervencionismo estatal e controles públicos na vida social. De outro lado, a guerra fria gerava uma verdadeira histeria "anticomunista" que identificava em toda e qualquer referência à "socialização da medicina”, ou intervenção do Estado sobre a saúde da população, uma ameaça ao valor das liberdades individuais. Há, consequentemente, um enfraquecimento das políticas de saúde pública, preteridas em favor do estímulo ao consumo individual e privado de assistência médica, em si mesma uma emergente área de produção capitalista 31 .

Semelhante enfraquecimento da saúde pública deu-se justamente no momento da chamada segunda revolução epidemiológica, com a emergência das doenças crônicas como a maior preocupação com saúde nas sociedades industrializadas. Na SHPH a adaptação a esse novo cenário foi lenta e traumática. Uma eloquente expressão das dificuldades enfrentadas encon- 
tra-se na experiência vivida por seu periódico, o American Journal of Hygiene. Com efeito, este periódico viveu, entre 1950 e 1960, a mais séria crise de sua história, desde a fundação, em 192132. A própria American Epidemiological Society, uma das principais instâncias de organização e direcionamento tecnopolítico da moderna Epidemiologia norte-americana, e de estreitas relações com a SHPH e com seu periódico (American Journal of Hygiene), passou a pressionar no sentido do abandono do velho perfil "sanitário" da revista, o que se reflete na mudança de seu nome para American Journal of Epidemiology, em 196533.

Nesse contexto, transforma-se também a geografia tecnopolítica da Epidemiologia, deslocando-se de Baltimore para Boston o "centro de gravidade" acadêmica da disciplina. Membro da Harvard School of Public Health (HSPH) desde o início de seu funcionamento, em 1922, Edwin B. Wilson já vinha trazendo para esta escola o que de mais avançado havia em termos de métodos quantitativos, levando-a progressivamente a sobrepujar, a partir dos anos 40, o prestígio que a Johns Hopkins tinha conquistado com Frost. Wilson, trabalhando em estreita parceria com Jane Worcester, deu ao trabalho de análise matemática dos fenômenos epidêmicos, amadurecido nos Estados Unidos por Frost, uma continuidade que a própria escola de origem do fundador da Epidemiologia norte-americana não conseguiria. Além disso, foram inúmeras as contribuições teóricas e metodológicas de Wilson ao campo, de modo que, quando ele se afastou de suas atividades, em 1945, Harvard já tinha uma sólida escola quantitativista, a de maior prestígio entre as suas similares norte-americanas 34 .

Na London School, o principal sucessor de Greenwood foi Austin Bradford Hill, um economista que se dedicou à estatística médica e que junto a um expressivo grupo de estudiosos do assunto, teve na Inglaterra um papel equivalente ao de Wilson no desenvolvimento das bases quantitativas da Epidemiologia moderna 35. E foi dessa tradição inglesa que Harvard importou o mais relevante nome para a consolidação de sua nova Epidemiologia: Brian MacMahon, conduzido à chefia do Departamento de Epidemiologia da HSPH, em 195836.

Contribuições metodológicas importantes para a consolidação desta nova fase do desenvolvimento da ciência epidemiológica foram também trazidas por outros estudiosos de métodos estatísticos aplicados ao estudo das doenças crônico-degenerativas. Um dos mais relevantes é o trabalho de Nathan Mantel e William Haenszel, pesquisadores do National Institute of Health. Esses autores desenvolveram métodos de análise estratificada e de teste de hipótese que permitiram adensar fortemente a validade proposicional dos estudos retrospectivos 37 . De modo análogo ao que acontecia com os estudos experimentais, o pesquisador podia agora escolher o tempo e os eventos que lhe interessavam, manuseando analiticamente suas implicações quanto à segurança das inferências estabelecidas. Não era mais preciso aguardar o correr do tempo dos laboratórios ou dos fatos para confirmar ou não uma hipótese causal. Assim como o médico, com base nos controles fornecidos pelo conjunto de evidências fornecidas pela história clínica, chegava a diagnósticos, prognósticos e intervenções plausíveis para determinado caso, também o epidemiologista, com os crescentes controles estatísticos e a versatilidade analítica fornecida pela análise estratificada, ficava então autorizado a enunciar diagnósticos, prognósticos e intervenções plausíveis com base na história epidemiológica de determinados grupos de casos.

Jerome Cornfield, do National Cancer Institute, foi outro nome de peso na consolidação da Epidemiologia do Risco. Entre as suas maiores contribuições figuram a introdução, em 1951, da odds ratio, uma aproximação matemática ao risco relativo com base em taxas "não verdadeiras" dos estudos tipo caso-controle, e o aperfeiçoamento da análise multivariada no estudo da interação entre fatores de riscos diversos, fundamental no caso das doenças crônico-degenerativas 37 . O domínio do tempo, isto é, a "sincronicidade" analiticamente produzida para o estudo dos eventos de interesse epidemiológico, foi enormemente expandido pela "virtualização" dos próprios eventos quando, pelas contribuições de Cornfield, a análise estatística passou a oferecer um razoável controle do grau de credibilidade das hipóteses causais estudadas por amostragens estatísticas.

Os estudos que passaram, desde então, a dominar a produção acadêmica da Epidemiologia caracterizaram-se não mais necessariamente como estudos populacionais, tampouco como estudos sobre exposição aos contactos infectantes. Os estudos epidemiológicos passaram a se configurar como estudos de associação (entre variáveis de exposição e variáveis de desfecho), seja de doenças infecciosas ou não, seja de exposição a fatores causais conhecidos ou não. Essa liberdade de objetos de estudo permitiu, por sua vez, que os estudos ganhassem um marcado caráter especulativo: a Epidemiologia já podia levantar e testar hipóteses causais para os mais diversos agravos, ou pelo menos inventariar fatores que aumentam a chance da ocorrência de um agravo ou que, ao contrário, protegem dele. Consolidava-se, assim, como uma ciência altamente formalizada, na qual a inferência passa a ser de base 
substantivamente matemática. O risco, seu conceito central, já possuía seus critérios próprios e autônomos para construir e validar enunciados, ganhando plena cidadania científica entre os saberes do campo da saúde. Falar de risco desde então é, imediata e rigorosamente, falar de grandezas matemáticas e elas são estimativas da chance de que a exposição a um fator (genético, ambiental, comportamental) possa estar causalmente associada a um determinado estado ou condição de saúde, dado um certo grau de incerteza da inferência, considerada pragmaticamente aceitável.

Em síntese, esta revisita histórico-epistemológica mostra que o risco era, no discurso da Epidemiologia da Constituição, um elemento de significado quase indistinto da linguagem ordinária, sendo um adjetivo para designar a condição de populações que viviam sob constituições epidêmicas, ou meios insalubres. No discurso da Epidemiologia da Exposição o risco começa a assumir um estatuto conceitual, passando a designar um processo sistemático de busca de validação de proposições sobre uma esfera determinada de aplicação. Não por acaso vai assumindo centralidade no discurso dessa ciência, a ponto de assumir-se que o objeto mesmo de inferência epidemiológica é o risco - nesse momento ainda entendido como chance de contacto entre agentes infecciosos e populações suscetíveis. Todavia, é na Epidemiologia do Risco que a linguagem do risco alcança sua formalização discursiva, tornando-se uma grandeza matemática. O risco não adjetiva, apenas, uma condição insalubre, tampouco se limita a designar inferências construídas mediante comportamentos estatísticos. Agora ele próprio é a expressão matemática da inferência epidemiológica. Risco passa a expressar, então, a racionalidade aplicada que é a Epidemiologia e, simultaneamente, a identidade discursiva da comunidade de epidemiologistas e os correspondentes alcances e limites de seus horizontes normativos (Tabela 1).

\section{Considerações finais}

Esta breve recuperação do desenvolvimento histórico-epistemológico do conceito de risco epidemiológico buscou contribuir para a compreensão sobre a formação desse discurso tão poderoso nas práticas de saúde da atualidade. Tal compreensão é fundamental para que possamos melhor dimensionar seu sentido prático. No caso da Epidemiologia do Risco, a presente recuperação histórica nos permitiu valorizar o grande esforço e o precioso legado representado pelo uso da lógica probabilística e das ferramentas estatísticas no raciocínio causal em saúde. Vimos como sua capacidade de aumentar nosso conhecimento, testando a associação de fatores das mais diversas naturezas com quaisquer fenômenos relevantes para a saúde, e seu poder de relacionar eventos passados com eventuais desfechos futuros, com crescente controle dos graus de incerteza dessa operação, expandiu os potenciais preventivos e curativos das práticas de saúde contemporâneas.

Por outro lado, percebe-se que a Epidemiologia alcançou seu elevado grau de formalização e rigor com base em um estreito diálogo com as ciências biomédicas e os métodos analíticoquantitativos, relegando a um plano secundário a interação teórica e metodológica com outros saberes e métodos também relevantes para a saúde, como as Humanidades e os procedimentos compreensivo-interpretativos. Com isso, os conhecimentos epidemiológicos experimentam dificuldades para lidar concretamente com os processos de saúde e doença. Em que pese o investimento da disciplina na construção de modelos de análise e inferência causal não lineares

Síntese das características dos estudos epidemiológicos nas diversas fases de desenvolvimento histórico-epistemológico da Epidemiologia.

\begin{tabular}{lcc}
\hline Perfil dos estudos & Epidemiologia da Constituição & Epidemiologia da Exposição \\
\hline Período & $1872-1929$ & $1930-1945$ \\
Definição & Populacional & Suscetibilidade \\
Caráter & Descritivo & Analítico \\
Matemática & Auxiliar & Estruturante \\
Meio & Conceitual & Lógico \\
Risco & Adjetivo & Substantivo \\
\hline
\end{tabular}

* Limite do período estudado, embora, em seus traços substantivos, julga-se ainda predominar este perfil na produção epidemiológica atual. 
e mecanicistas 38, há na leitura biomédico-quantitativa limites epistemológicos estruturais para apreender fenômenos cuja expressão objetiva reclama reflexão e crítica baseadas na experiência vivida; na atribuição de sentidos e significados dependentes de aspectos subjetivos, relacionais, simbólicos e valorativos imediatamente envolvidos. As implicações desses limites para as práticas de saúde vêm sendo amplamente debatidas, sendo apontadas repercussões que vão desde dificuldades da Epidemiologia sustentar seu rigor lógico frente à plurivocidade e contingência de suas categorias analíticas 39 até o paroxismo da responsabilização individual sobre o estado de saúde e doença de cada um 40.

\section{Resumo}

O raciocínio estatístico nas práticas de saúde foi disseminado pela Epidemiologia e é amplamente utilizado em todas as suas áreas de conhecimento. O objetivo deste artigo é revisitar o desenvolvimento histórico da Epidemiologia e a formalização do conceito de risco, responsável pelo uso da chance estatística como parte do raciocínio causal nas ciências da saúde. O período de estudo abrange os anos de 1872 a 1965 e sua base documental é constituída por trabalhos de periódicos científicos relacionados à construção do campo epidemiológico e outras publicações científicas. Foram identificadas três etapas de desenvolvimento da Epidemiologia: Epidemiologia da Constituição, Epidemiologia da Exposição e Epidemiologia do Risco, discutindo-se aspectos epistemológicos e sociossanitários que permitem compreender cada uma delas sob um ponto de vista histórico. Destaca-se a importância da reflexão crítica sobre a ciência epidemiológica e as suas relações com as práticas de saúde, de saúde pública em particular, para aperfeiçoar seu uso atual e propiciar sua constante e criativa reconstrução.

Risco; Epistemologia; Medicina Social
A Epidemiologia, como de resto qualquer discurso científico, é produzida por homens e mulheres em seus contextos históricos. São, portanto, respostas sociais aos desafios e possibilidades abertos em cada época e local, segundo confluências e conflitos de valores e necessidades. Assim, cabe-nos aprender com a reflexão histórica, potencializar os sucessos já alcançados, mas também construir novas formas para responder aos seus desafios 41 . Como destinatários e herdeiros dessa tradição discursiva, cumpre-nos buscar nos recursos existentes os meios para superar as limitações e necessidades percebidas a cada momento histórico, interna e externamente à nossa praxis científica.

\section{Agradecimentos}

Ao Prof. Euclides Ayres de Castilho por sua atenta leitura e sugestões para a redação final do artigo. 


\section{Referências}

1. Donnangelo MCF, Pereira L. Saúde e sociedade. São Paulo: Editora Duas Cidades; 1976.

2. Luz MT. Natural, racional, social: razão médica e racionalidade científica moderna. São Paulo: Editora Hucitec; 2004.

3. Canguilhem G. Le vivant et son milieu. In: Canguilhem G, editor. La connaissance de la vie. Paris: J. Vrin; 1985. p. 129-54.

4. Ayres JRCM. Epidemiologia e emancipação. São Paulo: Editora Hucitec; 2002.

5. Almeida Filho N. A clínica e a epidemiologia. Salvador: APCE/Rio de Janeiro: ABRASCO; 1992.

6. Japiassu HF. Introdução ao pensamento epistemológico. Rio de Janeiro: Editora Francisco Alves; 1988.

7. Bachelard G. A epistemologia. Lisboa: Edições 70; 1984.

8. Canguilhem G. Ideologia e racionalidade nas ciências da vida. Lisboa: Edições 70; 1977.

9. Habermas J. Teoria de la acción comunicativa. Madrid: Taurus; 1988.

10. Habermas J. Pensamento pós-metafísico. Rio de Janeiro: Editora Tempo Brasileiro; 1990.

11. Japiassu H. A revolução científica: dois modos de concebê-la. In: Japiassu H, organizador. A revolução científica moderna. Rio de Janeiro: Editora Imago; 1985. p. 81-112.

12. Gadamer HG. Sobre o círculo da compreensão. In: Gadamer HG, organizador. Verdade e método II. Petrópolis: Editora Vozes; 2002. p. 72-81.

13. Ayres JRCM. Sobre o risco: para compreender a epidemiologia. São Paulo: Editora Hucitec; 2008.

14. Rosen G. Uma história da saúde pública. São Paulo: Editora Hucitec/Editora da Unesp/Rio de Janeiro: ABRASCO; 1994.

15. Daniel TM. Wade Hampton Frost, pioneer epidemiologist 1880-1938: up to the mountain. Rochester: University of Rochester Press; 2004.

16. Fosdick R. La Fundación Rockfeller. México DF: Gandesa; 1957.

17. Fee E. Disease and discovery: a history of the Johns Hopkins School of Hygiene and Public Health, 1916-1939. Baltimore: The Johns Hopkins University Press; 1987.

18. Fichou JP. A civilização americana. Campinas: Editora Papirus; 1990.

19. Pettenkofer M. The value of health to a city. Bull Hist Med 1941; 10:487-503.

20. Winslow CEA. The conquest of epidemic disease: a chapter in the history of ideas. 2nd Ed. Madison: The University of Wisconsin Press; 1980.

21. Amsterdanka O. Demarcating epidemiology. Sci Technol Human Values 2005; 30:17-51.

22. Czeresnia D. Constituição epidêmica: velho e novo nas teorias e práticas da epidemiologia. Hist Ciênc Saúde-Manguinhos 2001; 8:341-56.
23. Sydenstricker E. Health in the New Deal. Ann Am Acad Pol Soc Sci 1934; 176:131-7.

24. Silverstein AM. A history of imunology. San Diego: Academic Press; 1989.

25. Stocks P. Infectiousness and immunity in regard to chickenpox, whooping cough, diphtheria, scarlet fever and measles. Proc R Soc Med 1930; 23 : 1349-68.

26. Greenwood M. On the statistical measure of infectiousness. J Hyg (Lond) 1931; 31:336-51.

27. Frost WH. Risk of persons in familial contact with pulmonary tuberculosis. Am J Public Health 1933; 23:426-32.

28. The Conference of epidemiologists. Am J Public Health (NY) 1927; 17:777-82.

29. Silva GR. Origens da medicina preventiva como disciplina do ensino médico. Revista do Hospital das Clínicas da Faculdade de Medicina da Universidade de São Paulo 1973; 28:91-6.

30. Starr P. The social transformation of American medicine. Washington DC: Basic Books; 1982.

31. Terris M. The epidemiologic revolution, national health insurance and the role of health departments. Am J Public Health 1976; 66:1155-64.

32. Fee E. Adapting to specialization: the founding, growth, and transformation of the American Journal of Hygiene. Am J Epidemiol 1991; 134:1030-40.

33. Change in name [Editorial]. Am J Epidemiol 1965; 81:1.

34. Curran JA. Founders of the Harvard School of Public Health. New York: Josiah Macy Jr. Foundation; 1970.

35. Farewell V, Johnson T. Woods and Russel, Hill, and the emergence of medical statistics. Statist Med 2010; 29:1459-76.

36. Terris M. The Society for Epidemiological Research (SER) and the future of epidemiology. Am J Epidemiol 1992; 136:909-15.

37. Greenland S. Evolution of epidemiologic ideas: annotated readings on concepts and methods. Chestnut Hills: Epidemiology Resources; 1987.

38. Rothman KJ, Greenland S, Lash TL. Epidemiologia moderna. Porto Alegre: Editora Artmed; 2011.

39. Almeida Filho N, Castiel LD, Ayres JRCM. Riesgo: concepto básico de la epiemiología. Salud Colect 2009; 5:323-44.

40. Castiel LD, Guilam MCR, Ferreira MS. Correndo o risco: uma introdução aos riscos em saúde. Rio de Janeiro: Editora Fiocruz; 2010.

41. Ayres JRCM, Paiva V, França Jr. I. From natural history of disease to vulnerability: changing concepts and practices in contemporary public health. In: Parker R, Sommer M, editors. Abingdon: Taylor and Francis; 2011. p. 98-107. (Routledge Handbook in Global Public Health).

Recebido em 17/Out/2010

Versão final reapresentada em 09/Abr/2011

Aprovado em 06/Mai/2011 